\title{
P03-014 - Biological therapy for autoinflammatory disorders
}

\author{
S Bujan Rivas ${ }^{1 *}$, Jl Arostegui Gorospe ${ }^{2}$, F Martinez Valle1, R Solans laque', JF Andres Cordon', J Ordi Ros ${ }^{1}$, \\ M Vilardell Tarres ${ }^{1}$ \\ From 7th Congress of International Society of Systemic Auto-Inflammatory Diseases (ISSAID) \\ Lausanne, Switerland. 22-26 May 2013
}

\section{Introduction}

Autoinflammatory diseases (AD) are innate immune system disorders, most of them with genetically identified basis. Usual therapeutic approach until last decade included non-steroidal antiinflamatories (NSAID), corticosteroids (CS) and colchicine. More recently, biological therapies (BT) have proved to be useful for refractory patients, especially those involving IL-1 $\beta$ blockade.

\section{Objectives}

To describe and analyze the experience with BT of a single center cohort of adult patients diagnosed with autoinflammatory disorders, including familial Mediterranean fever (FMF), TNF-receptor antagonist periodic syndrome (TRAPS), Muckle-Wells syndrome (MWS), undefined periodic fever (UPF), Blau syndrome (BS) and periodic fever, aphtous stomatitis, pharyngitis and adenitis (PFAPA).

\section{Methods}

Clinical files of 30 adult patients diagnosed with AD followed by the same clinical team of the Internal Medicine Service of Vall Hebron hospital were reviewed. Demographic, clinical, laboratory, and therapeutic data prior and after starting BT were collected. Data from BT treated patients included: reason for prescription, drug, dosage, treatment duration, response to treatment, tolerance and adverse effects related to the drug.

\section{Results}

13 out of 30 patients (5 FMF, 1 TRAPS, 4 MWS, 1 UPF, $1 \mathrm{BS}, 1$ PFAPA) received BT: 7 patients (5 FMF, $1 \mathrm{BS}$, 1 TRAPS) received anti-TNF (6 etanercept $50 \mathrm{mg} /$ weekly $\mathrm{SC}, 1$ patient adalimumab $40 \mathrm{mg} / 15 \mathrm{~d} \mathrm{SC}$ ) and 10 patients

${ }^{1}$ Internal Medicine, Hospital vall Hebron, Spain

Full list of author information is available at the end of the article
(3 FMF, 4 MWS, 1 UPF, 1 BS, 1 PFAPA) received rIL1RA anakinra $100 \mathrm{mg} / \mathrm{d}$ SC. 4 patients (2 FMF, $1 \mathrm{BS}$, 1 UPF) received first etanercept and were switched to anakinra due to incomplete / lack of response. Prescription reasons for BT were: first option 5/13 patients (etanercept for 1 TRAPS and anakinra for 4 MWS) and refractory disease in 8/13 patients (anti-TNF: 4 FMF, 1 UPF, 1 BS; anakinra: 3 FMF, 1 BS, 1 PFAPA, 1 UPF). Clinical improvement defined as reduction in number and/or intensity of attacks was achieved in $4 / 7$ patients treated with anti-TNF and in 9/10 patients receiving anakinra. 6 patients, all treated with anakinra, presented adverse effects: 6 patients local erythema at punction site $-2 / 6$ were moderate reactions-, and 1 patient transient alopecia. No opportunistic infection was detected.

\section{Conclusion}

Although BT are off-label indications in AD, its use has to be considered a helpful and safe therapeutic alternative for refractory cases of FMF, UPF, BS or PFAPA. In this serie, IL- $1 \beta$ blocking approach showed better response than anti-TNF with limited side effects.

\section{Competing interests}

None Declared.

\section{Authors' details}

${ }^{1}$ Internal Medicine, Hospital vall Hebron, Spain. ${ }^{2}$ Immunology, Hospital Clinic i Provincial, Barcelona, Spain.

Published: 8 November 2013

\section{doi:10.1186/1546-0096-11-S1-A212}

Cite this article as: Rivas et al.: P03-014 - Biological therapy for autoinflammatory disorders. Pediatric Rheumatology 2013 11(Suppl 1): A212.

\section{C)

๑ 2013 Rivas et al; licensee BioMed Central Ltd. This is an Open Access article distributed under the terms of the Creative Commons Attribution License (http://creativecommons.org/licenses/by/2.0), which permits unrestricted use, distribution, and reproduction in any medium, provided the original work is properly cited. 